\title{
Complications of Cervicofacial Cellulitis Supported in University Hospital Yalgado Ouedraogo
}

\author{
Yvette Marie Chantal Gyébré1* , Aboubacar Gouéta1, Noé Zaghré2, Moustapha Sérémé1, \\ Bertin Priva Ouédraogo ${ }^{1}$, Kampadilemba Ouoba ${ }^{1}$ \\ ${ }^{1}$ Service d'ORL et de CC-F, CHU-YO, Ouagadougou, Burkina Faso \\ ${ }^{2}$ Service d'ORL et de CC-F, Blaise Compaoré, Ouagadougou, Burkina Faso \\ Email: ”ycgyebre@gmail.com, egoueta@yahoo.com, zagnoe@yahoo.fr, serememoustapha@yahoo.fr, \\ bertin_oued@yahoo.fr, ouobakpd@yahoo.fr
}

Received 28 February 2016; accepted 7 May 2016; published 10 May 2016

Copyright (C) 2016 by authors and Scientific Research Publishing Inc.

This work is licensed under the Creative Commons Attribution International License (CC BY). http://creativecommons.org/licenses/by/4.0/

(c) (i) Open Access

\begin{abstract}
Introduction: The complications of cervicofacial cellulitis are one of the most serious emergencies Oto-Rhino-Laryngology (ORL). These complications are still observed in our context despite the advent of antibiotics. The aim of our study was to describe the clinical presentation and management of patients admitted to our institution for complications of cervicofacial cellulitis. Patients and Methods: It came from a retrospective study in the ORL service, a department of Yalgado Ouédraogo Hospital of Ouagadougou, between January 2005 and December 2014, during which all patients with cervicofacial cellulitis complications were identified. Results: We collected over 10 years, 69 cases of complicated cellulitis, a frequency of $54.3 \%$ of cervicofacial cellulitis and $2.3 \%$ of all hospitalizations. The group included $33 \%$ women and $67 \%$ men to 29 years of average age. The non-steroidal anti-inflammatory isolated was the main factor contributing $59.4 \%$. The front door was mainly dental 43.5\% and pharyngeal $36.2 \%$. The most frequent complications were mediastinitis thoracic dissemination $24.6 \%$, sepsis $21.7 \%$ and spontaneous fistula $20.3 \%$ with orostome or pharyngostome. Medico-surgical treatment was associated with a reanimation in most cases. The outcome was favorable in $\mathbf{7 9 . 7 \%}$ of cases. Mortality was $\mathbf{1 7 . 4 \%}$. Conclusion: The complications of cervicofacial cellulitis are frequent and often life-threatening. Their management is done in a multidisciplinary framework. The prevention and early treatment remain the pledge of their control.
\end{abstract}

\section{Keywords}

Complications, Cervicofacials Cellulitis

\footnotetext{
${ }^{*}$ Corresponding author.
}

How to cite this paper: Gyébré, Y.M.C., Gouéta, A., Zaghré, N., Sérémé, M., Ouédraogo, B.P. and Ouoba, K. (2016) Complications of Cervicofacial Cellulitis Supported in University Hospital Yalgado Ouedraogo. International Journal of Otolaryngology and Head \& Neck Surgery, 5, 115-120. http://dx.doi.org/10.4236/ijohns.2016.53019 


\section{Introduction}

The cervicofacial cellulitis and fasciitis Anglos-Saxons are infections of fatty cellular tissue of the head and neck [1]. They carry an extensive necrotizing affection along the fascial divisions of the face and neck to the mediastinum [2]. Then they are the source of complications.

In our socio-economic context of poverty, the evolution is often marked by complications and these complications can be life-threatening [2]-[4].

Several authors [4]-[6] in their series have found that the most frequent complications were constituted by mediastinitis, sepsis and pneumonia. The mediastinitis is potentially the most deadly.

The complicated cervicofacial cellulitis is dreadful disease that poses therapeutic management difficulties. They are still observed in our practice despite the advent of antibiotics. The absence of similar studies of these complications in Burkina Faso led us to conduct this study. The aim of this study was to describe the clinical presentation and management of patients admitted to our institution for this pathology.

\section{Patients and Methods}

This is a retrospective study conducted in the Oto-Rhino-Laryngology (ORL) service, a department of Yalgado Ouédraogo hospital from January 2005 to December 2014. This study included all patients who experienced a complication of cervicofacial cellulitis. Of 127 cases of cervicofacial cellulitis supported, 69 complicated cellulitis records were retained.

For each folder, were evaluated: age, sex, field, risk factors, the gateway, the clinical signs of severity, the germ causes, types of complications, treatment and evolution.

The data collection was performed using a structured questionnaire used collection sheet. The data were collected from clinical records of patients, consultation records.

We included in our study the patients who presented a complication of cellulitis, either at the entrance or during hospitalization.

We considered complication, the occurrence on a cervicofacial cellulitis a mediastinitis, sepsis, cutaneous necrosis with orostome or pharyngostome, a lung disease, thrombosis of the jugular vein, meningoencephalitis, osteitis and multiple organ failure.

The data were analyzed using Epi Info 3.5.1 in its French version. The ethical considerations have been approved by the patient and ethics and compliance committee.

\section{Results}

In 10 years, 69 patients with complications of cervicofacial cellulitis were registered, representing an annual incidence of 6.9 cases. Complications cellulite represented $2.3 \%$ of all hospitalized patients and $54.3 \%$ of cervicofacial cellulitis. Our patients were 7 months to 70 years with an average age of 29 years. The dominance was masculine with 39 men $(67 \%)$ for 30 women $(33 \%)$ of the patients is a sex ratio of 1.3 . On admission, all patients have received first isolated anti-inflammatories and antibiotics.

The contributing factors were constituted by anti-inflammatory drugs (NSAIDs) (59.4\%), diabetes (20.3\%), intoxication with alcohol and tobacco (14.5\%), the immunosuppression (2.9\%), pregnancy $(2.9 \%)$.

The front door was especially dental $(43.5 \%)$ and amygdala $(36.2 \%)$. Other entry points were found: sinus $(5.8 \%)$, trauma broken skin $(4.4 \%)$, parotid $(1.4 \%)$, indeterminate $(8.7 \%)$.

At the clinical level, the average time of consultation was 12 days and ranged from 2 and 120 days. The inflammatory swelling cervicofacial or cervical-thoracic, the tight trismus and the dysphagia were the most frequent signs. The clinical signs are presented in the following table (Table 1).

Fever was observed in 49 patients $(71 \%)$ and ranged between $38^{\circ} \mathrm{C}$ and $40^{\circ} \mathrm{C}$.

The scanner (brain, cervicofacial, cervicothoracic) was performed in 32 patients. It was a capital contribution in the diagnosis of certain complications of cellulitis (Figure 1).

The complications were diagnosed at the entrance to $54.3 \%$ and in $45.7 \%$ of cases per hospital. The most frequent complications were mediastinitis in 17 cases $(24.6 \%)$ followed by sepsis in 15 cases $(21.7 \%)$, spontaneous fistula and diffuse cutaneous necrosis in 14 cases $(20.3 \%)$ with orostomes (5 cases) and pharyngostomes ( 9 cases) (Figure 2), and pneumonia in 12 cases (17.4\%).

Other types of complications were constituted by thrombosis of the jugular vein in 5 cases $(7.2 \%)$, meningoencephalitis in 3 cases $(4.3 \%)$, osteitis ramus in 2 cases $(2.9 \%)$, and organ failure in 1 case $(1.4 \%)$. 
Table 1. Apportionment of clinical signs.

\begin{tabular}{ccc}
\hline Clinical signs & Effective (n) & Percentage (\%) \\
\hline Inflammatory tumefaction & 69 & 100 \\
Tight trismus & 58 & 84 \\
Dysphagia & 49 & 71 \\
fistula endobuccal & 28 & 40.6 \\
Chest pain & 13 & 18.8 \\
Moderate dyspnea & 9 & 13 \\
Skin necrosis & 4 & 5.8 \\
Crepitation neizeuse sub cutaneous & 3 & 4.3 \\
\hline
\end{tabular}
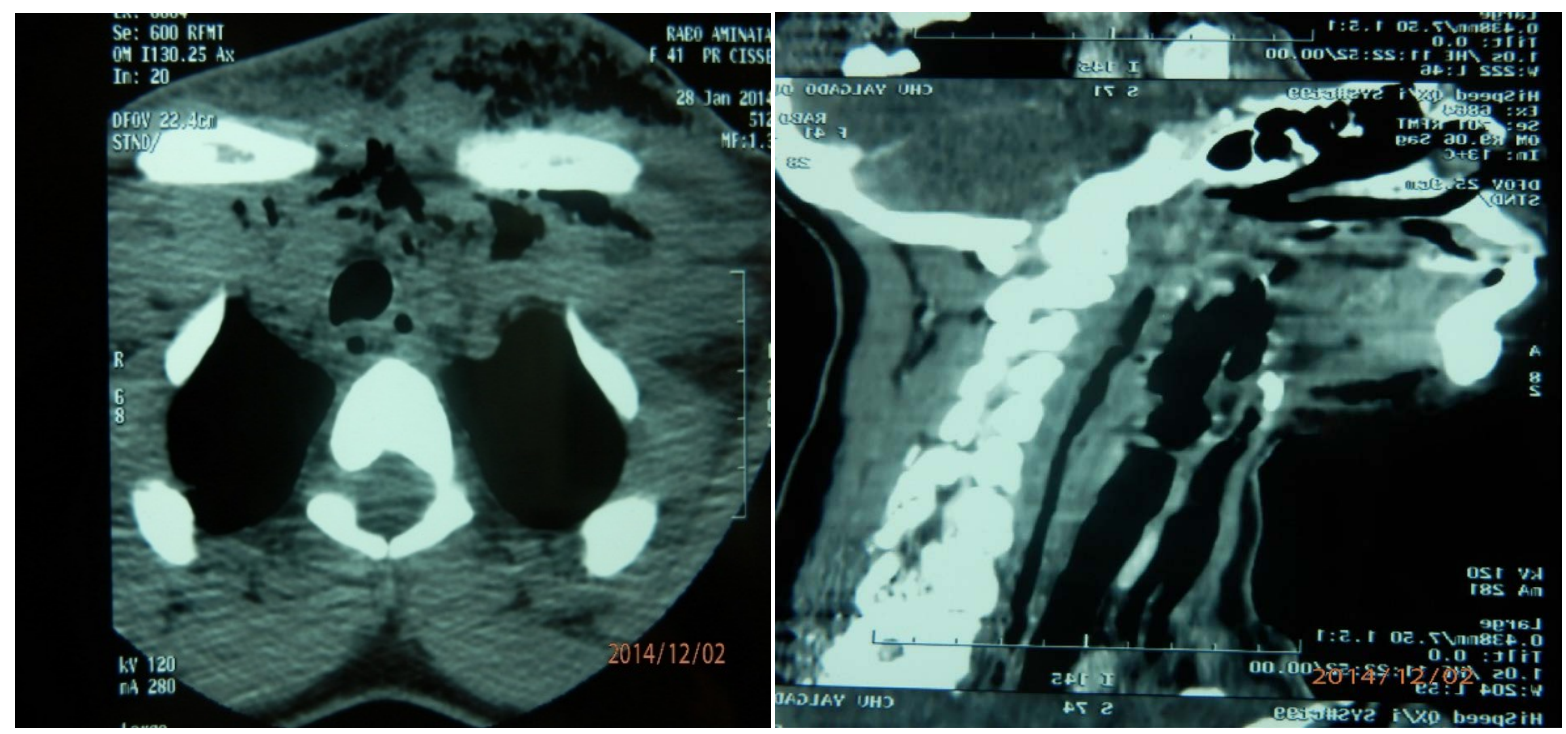

Figure 1. Axial and sagittal objectifying a cervical-mediastinal emphysema in favor of mediastinitis.

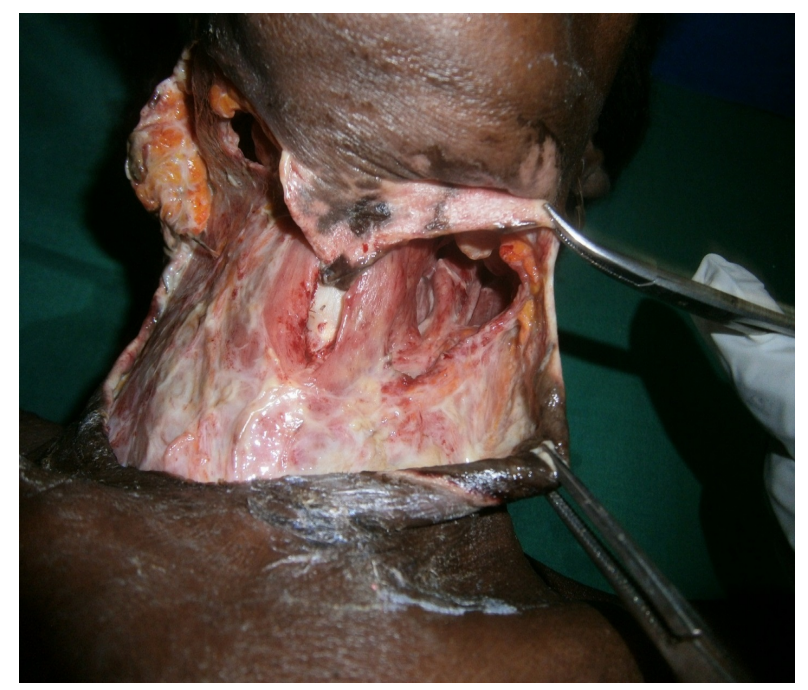

Figure 2. Pharyngostome and orostome.

The evolution of the jugular vein thromboses was marked by vascular rupture, 1 case of aorto-esophageal fistula having led hematemesis of great abundance and patients, 1 case of ischemic stroke, 1 case of pulmonary 
embolism (Lemierre's syndrome). No cases of cerebral venous thrombosis were found.

Bacteriological examination was performed in all patients. It was positive in $42 \%$ of cases. The germs were identified Streptococcus in 12 cases (41.3\%), Pseudomonas aeruginosa in 7 cases (24.1\%), Staphylococcus in 07 cases (24.1\%), Escherichia coli in 2 cases (6.9\%), Haemophilus influenzae in 1 case (3.4\%). Other samples were sterile $58 \%$.

The treatment was medical and surgical. The initial antibiotic therapy was probabilistic then it was adapted according to the germs found. So $46 \%$ had ceftriaxone-metronidazole-gentamicin, $23 \%$ amoxicillin-clavu-lanic acid-metronidazole and $31 \%$ amoxicillin-clavulanic acid. The average duration of antibiotic treatment parenterally was 1 week. Surgical treatment was performed in all patients. This treatment was associated with a reanimation of which 6 cases received oxygen therapy. Hospital stay ranged from ten (10) and thirty five (35) days with an average of fifteen days.

The evolution was favorable in 55 cases (79.7\%) (Figure 3). We scored 2 out against medical advice and 12 deaths (17.4\%). Among the deaths, 04 cases occurred in an array of septic shock, 5 cases and 2 cases of mediastinitis in an array of respiratory distress to the block and 1 case during hematemesis probably due to vascular rupture by aorto-esophageal fistula.

\section{Discussion}

The complicated cervicofacial cellulitis is relatively frequent in our practice, $2.3 \%$ of hospitalized patients. Its frequency varies depending on the series. It would be exceptional to some authors [2]-[4]. It is potentially deadly, imposing a prevention and early management of cervicofacial cellulitis. It is the prerogative of adults 29 years of male middle age. Our results are according with the literature [2] [3] [5] [7].

The average time of consultation was 12 days in our series. The same was done by Sérémé [8]. Several reasons underlie this long period: self-medication, low income patients and their therapeutic route often through traditional medicine. The corollary of this is the admission of the patients in stage complications.

Severe dysphagia, painful swelling, fever and trismus were the most commonly reported warning signs in our study and in the literature [3] [5]. Chest pain and signs of neurological localizations are sometimes noted. They should require the production of a scanner is radiological examination of choice. In emergency, it confirms the diagnosis of cellulitis and specifies the type of complications. It will adapt the treatment protocol and preserve the vital prognosis of the patient [9]. However its high cost is its limit. It was a capital contribution in our study. She clarified the type of complication.

The mediastinitis, sepsis and pneumonia complications frequently encountered in our series, have also been reported by several authors [4]-[6]. They should be raised before a frank infectious syndrome, dyspnea, or the appearance of snow diffuse subcutaneous crepitus cervicothoracic, signing the gangrenous form of cervicalmediastinal rapid expansion. The onset of chest pain and pre-sternal redness indicate a mediastinal disease [5]. Meningoencephalitis would be secondary to septic metastasis from a jugular vein thrombosis or an extension to

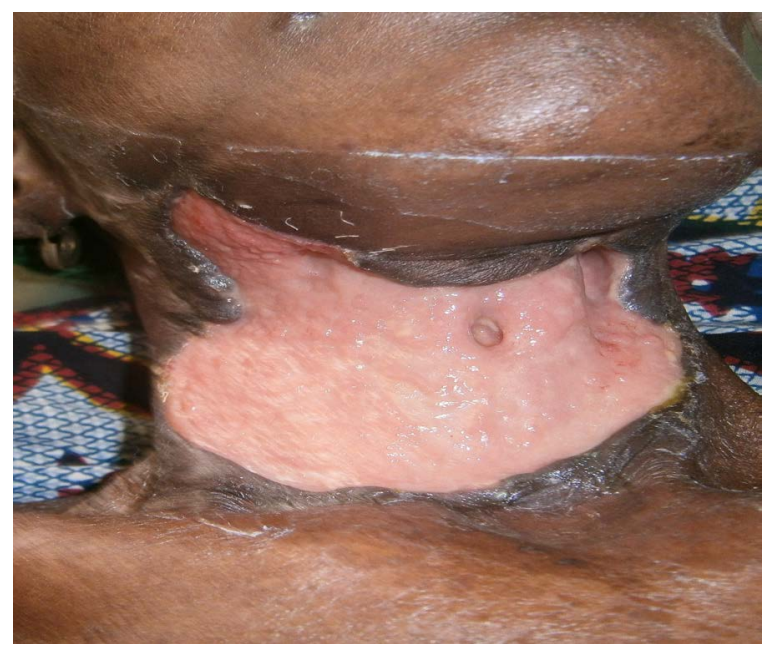

Figure 3. Healing after medical and surgical treatment. 
the cervical spine with myelitis. Infection of the cervical wall and the vascular sheath favored the occurrence of septic thrombosis of the vein will eroded the vascular wall with probably an aorto-esophageal fistula. The fistula is related to the long consultation period.

The main risk factors found in our series are isolated NSAIDs $(59.4 \%)$ and diabetes $(20.3 \%)$. Promote diabetes complications by immunosuppression that leads [10]. NSAIDs used in isolated form or in the absence of effective antibiotics, mask the symptoms favoring the spread of infection by a depressive effect on the humoral immune defense mechanisms [11] [12]. They thus predispose to serious infections. They are to avoid an uncontrolled infection [2] [13]. It's more a recommendation of the Center for Prevention and Disease Control in the United States of America [14]. The dental front door was the most frequent in our series and by several authors [2] [8]. This high incidence is related to poor oral hygiene [2] [6].

Biologically, bacteriological results could levy vary depending on the series. These samples were sterile in 58\% of cases in our work. For Miloundja, this rate was $25 \%$ [2]. This is a reflection of the pre-hospital use of antibiotics sterilizes the infectious focus. The infection is most often polymicrobial mixed, and the predominance of anaerobes unanimous authors [6] [12]. The presence of such a polymicrobial flora is responsible for a kind of synergism leading to the increased virulence of the infection with a rapid tissue necrosis [15].

The treatment of complications of cervicofacial cellulitis is medical and surgical combined with a suitable reanimation [2] [12]. This reanimation is effective only in an intensive care unit (ICU) is often not possible in our context. Its management is multidisciplinary. All this makes this difficult management. The choice of antibiotic therapy is extremely difficult because in most cases it is initially probabilistic and secondarily adapted to the antibiogram. The idea is to use antibiotics effective on both aerobic and anaerobic.

All patients have benefited from a surgical drainage. This drainage may require in some cases mediastinitis thoracotomy [6]. Patients who experienced thrombosis type complications benefited from anticoagulant therapy.

The early diagnosis is a key element in the management and prognosis of cervcicofacial cellulitis. More than half of patients were received at the stage of complications hence the need for education of the population on the early consultation.

The prognosis of these complications is also related primarily to the field, the effectiveness of the initial treatment, including the isolation of the causative organism, is a crucial step [3]. For McHenry [16] a delay between admission and more than 90 hour surgery is the main risk factor for mortality. The percentage of deaths in the literature varies between $7 \%$ and $50 \%$ [2] [17]. In our series, we registered $17.4 \%$ of deaths was 1 case of death of 5 cervicofacial cellulitis complicated. We agree with Lindner and Gauzit [18] [19] that, the cervicofacial cellulitis is a deadly disease, killing one patient on $4-5$ entrants. The cellulites are medical and surgical emergencies redoubtable need to know to diagnose and support as soon as possible. Untreated, these infections are inevitably life-threatening.

\section{Conclusion}

The complications of cervicofacial cellulitis are frequent in our context and serious as they undertake the vital or functional prognosis. Their support is heavy and can only be conceived within a multidisciplinary framework. The early treatment of cervicofacial cellulitis and better prevention is the pledge of the control of these infections.

\section{References}

[1] Benbouzid, M.A., Benhamou, A. and El massaoudi, A. (2004) Les cellulites cervico-faciales à propos de 8 cas. ESP Med, 11, 86-89.

[2] Miloundja, J., Assini Eyogho, S.F., Mandji Lawson, J.M., Ondounda, M., Koumba, J.S., Lekassa, P., Inibend, M. and N'zouba, L. (2011) Cellulites cervico-faciales diffuses: 32 cas vus à Libreville. Sante, 21, 153-157.

[3] Lakouichmi, M., Tourabi, K., Abir, B., Zouhair, S., Lahmiti, S. and Hattab, N.M. (2014) Les cellulites cervico-faciales graves, facteurs et critères de gravité. The Pan African Medical Journal, 18, 57. http://dx.doi.org/10.11604/pamj.2014.18.57.3702

[4] Dubernard, C., Bellanger, S., Chambon, G., Léon, H., Torres, J.H. and Lozza, J. (2009) Cellulite d'origine dentaire engageant le prognostic vital: à propos d'un cas. Médecine Buccale Chirurgie Buccale, 15, 119-125. http://dx.doi.org/10.1051/mbcb/2009010

[5] Huy, P.T.B., Blancal, J.P., Verillaud, B., Mebazaa, A. and Herman, P. (2011) Les cellulites cervico-faciales. Une grave 
urgence ORL. Bulletin de l'Académie Nationale de Médecine, 195, 661-678.

[6] Righini, C.A., Motto, E., Ferretti, G., Boubagra, K., Soriano, E. and Reyt, E. (2007) Cellulites extensives et médiastinite descendante nécrosante. Ann Otolaryngol Chir Cervicofac, 124, 292-300. http://dx.doi.org/10.1016/j.aorl.2007.02.001

[7] Makeieff, M., Gresillon, N. and Berthet, J.P. (2004) Management of Descending Necrotizing Mediastinitis. Laryngoscope, 114, 772-775. http://dx.doi.org/10.1097/00005537-200404000-00035

[8] Sérémé, M., Ouédraogo, B., Gyébré, Y., Ouattara, M. and Ouoba, K. (2010) Cellulites cervico-faciales à propos de 26 cas. La Revue africaine d'ORL et de Chirurgie cervico-faciale, 9, 23-28.

[9] Azizi, J.E.L., Alaoui, E.L., Ayoubi, A., Hadjkacem, H., Benbouzid, A., Kzadri, M., Chakir, N., Hassani, M.R. and El Jiddane, M. (2015) Imagerie des Cellulites cervico-faciales diffuses. A propos de 43 cas. Rabat Maroc. Consulté le 1 July.

[10] Diallo, O.R., Balde, N.M., Conde, B., Camara, S.A.T. and Bahat, A.T. (2006) Les cellulites cervico-faciales chez le patient diabétique au CHU de Conakry. Rev Col Odonto-Stomatol Afr Chir Maxillo-fac, 13, 13-16.

[11] Chaplain, A., Gouello, J.P. and Dubin, J. (1996) Cellulites cervicales nécrosantes aigues à porte d'entrée pharyngée: rôle possible des anti-inflammatoires stérö̈diens et non stéroïdiens: à propos de 5 observations. Rev Laryngol Otol Rhinol, 117, 377-380.

[12] Cristofaro, M.G., Giudice, A., Colangeli, W., November, D. and Giudice, M. (2012) Cervical Facial Necrotizing Fasciitis with Medistinic Spread from Odontogenic Origin Two Case Reports. Annali Italiani di Chirurgia, 30, 83.

[13] Forbes, N. and Rankin, A.P. (2001) Necrotizing Fasciitis and Non Steroidal Anti-Inflammatory Drugs: A Case Series and Review of the Literature. New Zealand Medical Journal, 114, 3-6.

[14] Benariba, F., Ammar, H. and Alouane, M. (2007) Cellulite cervico-faciale: à propos de 5 cas. Médecine et Armées, 35, 171-174.

[15] Gallo, S., Karligkiotis, A., Lenzi, R., Castelnuovo, P. and Dallan, I. (2012) Necrotizing Craniocervical Soft Tissue Infections: Clinical Experience and Personal Considerations. Case Reports in Otolaryngology, 2012, Article ID: 489638.

[16] McHenry, C.R., Piotrowski, J.J., Petrinie, D. and Malangoni, M.A. (1995) Determinants of Mortality for Necrotizing Soft-Tissue Infections. Annals of Surgery, 221, 558-565. http://dx.doi.org/10.1097/00000658-199505000-00013

[17] Lee, J.W., Immerman, S.B. and Morris, L.G. (2010) Techniques for Early Diagnosis and Management of Cervicofacial Necrotising Fasciitis. The Journal of Laryngology \& Otology, 124, 759-764. http://dx.doi.org/10.1017/S0022215110000514

[18] Lindner, H.H. (1986) The Anatomy of the Fascia of the Face and Neck with Particular Reference to the Spread and Treatment of Intraoral Infections (LUDWIG'S) That Have Progressed into Adjacent Fascial Spaces. Annals of Surgery, 204, 705-714.

[19] Gauzit, R. (2006) Infections cutanées graves: définition, caractéristiques cliniques et Microbiologiques. Annales Françaises d'Anesthésie et de Réanimation, 25, 967-970. http://dx.doi.org/10.1016/j.annfar.2006.03.018 